\title{
A CASE OF NON-HODGKIN'S LYMPHOMA WITH RECURRENT PERICARDIAL EFFUSION AND CHEST WALL MASS
}

\author{
ALAM MB ${ }^{1}$, DASGUPTA R ${ }^{2}$, AHMED $\mathrm{S}^{3}$, FERDOUS MAR ${ }^{3}$
}

\begin{abstract}
:
Recurrent pericardial effusion as a presenting feature of Non-Hodgkin's Lymphoma is uncommon. Here we describe the case of an 18-year-old male presented with severe respiratory distress with a chest wall swelling. During the course of his three months illness, he was hospitalized two times with few days interval for similar attack of dyspnoea without any chest wall mass. Each time there was pericardial effusion and pericardiocentesis was done but no conclusive diagnosis could be made. Finally, when he came to us with a chest wall mass in addition to pericardial effusion, Non-Hodgkin's Lymphoma was confirmed by FNAC of that mass. Symptomatic improvement was achieved after first cycle of chemotherapy with CHOP.
\end{abstract}

Keywords: Non-Hodgkin's lymphoma, recurrent pericardial effusion, chest wall mass.

J Dhaka Med Coll. 2008; 17(2) : 138-141.

\section{Introduction:}

The Non-Hodgkin's lymphomas are a heterogeneous group of lymphoproliferative malignancies having different patterns of behavior and responses to treatment. Like Hodgkin lymphoma, NHL usually originates in lymphoid tissues but NHL, however, is much less predictable than Hodgkin lymphoma with a far greater predilection to disseminate to extranodal sites ${ }^{1}$. Types of non-Hodgkin's lymphoma vary significantly in their severity, from indolent to very aggressive. The WHO classification (2001) of non- Hodgkin's lymphoma is based on the Revised European American Lymphoma (REAL) system and it includes aggressive or highly aggressive varieties. Most patients present with painless, superficial lymph node enlargement. Systemic symptoms include fever, sweats \& weight loss. Commonly involved extranodal sites are gastrointestinal tract, lung, brain, testes, thyroid $\& \operatorname{skin}^{2}$. Pericardial effusion as the primary manifestation of high grade malignant lymphoma is a very rare condition ${ }^{3}$. On the other hand, among primary chest wall masses, chest wall lymphoma is uncommon, accounting for less than $2 \%$ of chest wall soft tissue tumours ${ }^{4,5}$. Here we describe a case of NonHodgkin's lymphoma with recurrent pericardial effusion where multiple attempts of pericardiocentesis failed to yield a confirm diagnosis.

\section{Case report:}

An 18 years old male was presented with the complaints of respiratory distress with generalized swelling of whole body for 10 days. It was associated with a right anterior chest wall mass for the same duration. The person was relatively well about three months back. Over the last three months he was admitted into two different hospitals with exertional dyspnoea and occasional mild fever. Each time pericardial fluid was aspirated and patient was given conservative management without reaching a confirmatory diagnosis. Lastly he came to us with gradual worsening of respiratory distress once again with generalized body swelling and a chest wall mass for 10 days. There was no fever during last presentation and occasional chest pain was present. His past medical history was not significant and none of his family members suffered from similar sort of disease. The person

1. Associate Professor, Department of Medicine, Dhaka Medical College, Dhaka.

2. Assistant Professor, Department of Medicine, Dhaka Medical College, Dhaka.

3. Post graduate trainee, Department of Medicine, Dhaka Medical College, Dhaka.

Correspondence : Dr. Md. Billal Alam 
was non-smoker and had the history of working in a plastic factory for 3 years. General examination revealed that the patient was ill looking, tachypnoic, body built was average and decubitus was sitting. His pulse was 90 beats / minute, blood pressure was $120 / 60 \mathrm{~mm}$ of $\mathrm{Hg}$ and temperature was mildly raised. He was mildly anaemic, non-icteric and moderate leg oedema was found. Lymph nodes were not enlarged. On chest examination, a hard, nearly rounded mass was found over the right anterior chest that was firmly adherent to the underlying structures but the overlying skin was free. Trachea was shifted to left. Percussion note and auscultatory findings of the chest revealed a bilateral pleural effusion. Heart sounds were soft and no added sound was found. On examination of the abdomen, there were ascites and hepatomegaly. Other systemic examination revealed no abnormality. Complete blood count revealed a neutrophilic leukocytosis $\left(19.53^{\prime} 10^{9} / \mathrm{L}\right)$ with high ESR (41 $\mathrm{mm}$ in $1^{\text {st }}$ hour) and Hb conc. was $11.30 \mathrm{gm} / \mathrm{dl}$. PBF also showed neutrophilic leucocytosis. Routine examination of urine, random blood sugar, serum creatinine, uric acid and bilirubin were within normal limits. His serum LDH and SGPT levels were raised (705 U/L and $106 \mathrm{U} / \mathrm{L}$ respectively) and bone marrow examination revealed normal active marrow. Pleural fluid biochemistry showed protein $36 \mathrm{gm} / \mathrm{L}$, sugar $43 \mathrm{mg} / \mathrm{dl}$ and cytology showed $2500 / \mathrm{mm}^{3}$ of total WBC with $100 \%$ lymphocytes. Pericardial fluid biochemistry showed protein $6.40 \mathrm{gm} / \mathrm{dl}$, sugar $18 \mathrm{mg} / \mathrm{dl}$ and cytology showed WBC $1000 / \mathrm{mm}^{3}$ with $60 \%$ lymphocytes, $40 \%$ polymorphs. No malignant cell or acid fast bacilli (AFB) was found in either of these fluids. Chest X-ray showed a bi-lateral pleural effusion and cardiomegaly. Echocardiography revealed moderate pericardial effusion with no features of cardiac tamponade. CT-chest showed a chest wall mass with intra-thoracic extension, pericardial effusion and bi-lateral huge pleural effusion with complete collapse of both lower lobes of lungs. FNAC from chest wall swelling revealed Non-Hodgkins Lymphoma of high grade. After diagnosis, chemotherapy was started with CHOP regimen. Considerable symptomatic improvement was noticed after first cycle of chemotherapy.

\section{Discussion:}

Patients with recurrent pericardial and pleural effusion should be investigated for occult malignancies, rheumatological diseases and chronic infections such as HIV, tuberculosis, hepatitis, and syphilis ${ }^{6}$. Cardiac involvement in systemic lymphoma has been reported in up to $20 \%$ of cases ${ }^{7}$. But massive pericardial effusion as the primary manifestation of highgrade malignant lymphoma is a very rare condition. Pericardial effusion in patients with lymphoma might be due to direct involvement of the pericardium and/or hematogenous spread $^{3}$. Massive pericardial effusion can also be seen in two very rare forms of non-Hodgkin's lymphoma (NHL): primary cardiac lymphoma (PCL) and primary effusion lymphoma (PEL). The former one involves only heart and pericardium and typically seen in patients infected with HIV. The later one is characterized by growth_in serous body cavities without detectable tumour masses and in addition to HIV infection it has an association with human herpes virus ${ }^{7}$. Infiltration of pericardium by Non-Hodgkin's lymphoma may also give rise to constrictive pericarditis and cardiac tamponade ${ }^{8}$. Laboratory Hospital Universitario de Caracas, Venezuela, to detect pericardial and myocardial abnormalities at presentation for initial clinical staging of NonHodgkin's lymphoma conducted a prospective study. Thirty-two patients, ranging from 15 to 65 (mean, 46) years of age, were studied. Echocardiographic examination revealed that 17 patients (53\%) had pericardial effusion. If tamponade develops and treated properly, the presence of pericardial effusion has no adverse effect on survival at 1 year ${ }^{9}$. Recurrent pericardial effusion of our patient was also associated with a chest wall mass during his last hospitalization ( $3^{\text {rd }}$ time). Among primary chest wall masses, chest wall lymphoma is uncommon and is less than $2 \%$ of chest wall soft tissue tumors 4,5. Malignant lymphoma presenting as a solitary chest wall mass is a rare entity 10,11. Disseminated systemic lymphoma often has involvement of the mediastinum but only $5 \%$ to $10 \%$ of patients 
with lymphoma present with primary mediastinal lesions. Most mediastinal lymphomas are seen in the anterosuperior mediastinum. Primary mediastinal NonHodgkin's lymphoma is found in all age groups but is more common in women in the third and fourth decades ${ }^{12}$. From the CT-chest of our patient, it was revealed that the chest wall mass extended behind up to the anterior mediastinum. Masses in the anterior compartment are more likely to be malignant than those found in the other mediastinal compartments ${ }^{13}$. A retrospective survey was conducted in Taipei Veteran General Hospital from 1991 to 2004. There were 157 patients with an initial presentation of a chest wall mass. Among these 157 patients, primary nonHodgkin's lymphoma was diagnosed in 7 of them. Diagnostic methods included fine-needle aspiration, incision biopsy, and excision biopsy. Patients with tumors arising from axillary lymph nodes or mediastinal lymphadenopathy with chest wall extension were excluded in the study ${ }^{14}$. For early diagnosis of such a case with recurrent pericardial effusion, pericardial fluid analysis plays a major role specially when extensive tumour search does not reveal any tumour formation or even any enlarged lymph node for biopsy (as in PCL and PEL). Cytology of pericardial fluid may show huge lymphocytes and highly atypical lymphoid cells (NHL-DIAG) ${ }^{2}$. Currently used other diagnostic methods include immunocytochemistry, DNA image cytometry (ICM-DNA), polymerase-chainreaction (PCR) and cytogenetic analysis. Nuclear DNA measurement by ICM-DNA improves diagnostic accuracy of conventional cytology for malignant cell detection in body cavity effusions ${ }^{3,7}$. Pericardial and pleural fluid study of our patient showed exudative nature of fluids with lymphocyte predominance and there was no malignant cell or AFB. We didn't go for extensive immunohistochemical analysis of pericardial fluid because he had an obvious chest wall mass during his last time hospitalization and we got an opportunity to perform FNAC from the mass and report was consistent with Non-Hodgkin's lymphoma of high grade. The primary treatment of choice for Non-Hodgkin's lymphoma is chemotherapy.
Literature survey reveals that R-CHOP therapy is better than conventional CHOP therapy in case of primary cardiac lymphoma ${ }^{15}$. Surgery followed by adjuvant chemotherapy can provide satisfactory outcome in some patients in whom the chest wall lymphoma was the only site of disease. But when mediastinum is involved, surgical resection can play no role ${ }^{14}$. In conclusion, our case illustrates the matter that a patient with Non-Hodgkin's lymphoma may present with recurrent pericardial effusion $\&$ chest wall mass. It shows the importance of keeping the diagnosis of Non-Hodgkin's lymphoma when definitive diagnosis could not be made in a patient with recurrent pericardial effusion.

\section{References:}

1. Adult Non-Hodgkin Lymphoma Treatment, National Cancer Institute, U.S. National Institute of Health. Website http://www.cancer.gov.

2. Gallagher CJ, Lister TA, Johnson MJ, Davies A. In: Kumar P, Clark M. eds. Clinical medicine, $7^{\text {th }}$ ed. Edinburgh: WB Saunders; 2009. p.475-84.

3. Çay S, Durak A, Aydoðdu S, Turhan N. Massive pericardial effusion as the primary manifestation of high grade malignant lymphoma, Türk Kardiyol Dern Arc (Arch Turk Soc Cardiol). 2009: 37(8): 578-9.

4. King RM, Pairolero PC, Trastek VF, Piehler JM, Payne WS, Bernatz PE. Primary chest wall tumors factors affecting survival. Ann Thorac Surg. 1986; 41: 597-601.

5. Tateishi U, Gladish GW, Kusumoto M, Hasegawa $\mathrm{T}$, Tsuchiya R, Moriyama $\mathrm{N}$, et al. Chest wall tumors: radiologic findings and pathologic correlation: part 2. malignant tumors. Radiographic. 2003; 23: 1491-1508.

6. Navaneethan SD, Venkatesh S, Shrivastava R, Mehta J, Israel R. Recurrent pleural and pericardial effusions due to sarcoidosis. PLoS Med. 2005; 2(3): e63.

7. Maedera M, Spielerb P, Krapfac R, Diethelma M. Cytologically malignant lymphoid pericardial effusion with benign clinical outcome. Swiss Med Weekly. 2005; 135: 377-81.

8. Noma T, Mizushige K, Kohno M. Constrictive pericarditis caused by infiltration of nonHodgkin's lymphoma. Heart. 2002; 88:148.

9. Acquatella GC, Roura ET, Maury AJ, Stern RO, Acquatella H. High incidence of pericardial effusion in non-Hodgkin's lymphoma: usefulness 
of echocardiography. Eur J Cancer Clin Oncology. 1982; 18(11): 1131-6.

10. Faries PL, D'Ayala M, Santos GH. Primary immunoblastic B cell lymphoma of sternum. J Thorac Cardiovasc Surg. 1997; 114: 684-5.

11. Press GA, Glazer HS, Wasserman TH, Aronberg DJ, Lee JKT, Sagel SS. Thoracic wall involvement by Hodgkin disease and non-Hodgkin lymphoma: CT evaluation. Radiology. 1985; 157: 195-8.

12. Sekiguchi N, Nishimoto J, Tanimoto K, Kusumoto $\mathrm{S}$, Onishi $\mathrm{Y}$, Watanabe $\mathrm{T}$, et al. Primary mediastinal large B-cell lymphoma: a singleinstitution clinical study in Japan. Int $\mathrm{J}$ Hematol. 2004; 79: 465-71.
13. Davis RD Jr, Oldham HN Jr, Sabiston DC Jr. Primary cysts and neoplasms of the mediastinum: recent changes in clinical presentation, methods of diagnosis, management and results. Ann Thorac Surg. 1987; 44: 229.

14. Hsu PK, Hsu HS, Li AFY, Wang LS, Huang BS, Huang $\mathrm{MH}$, et al. Non-Hodgkin's Lymphoma Presenting as a large chest wall mass. Ann Thorac Surg. 2006; 81: 1214-8.

15. Nonami A, Takenaka K, Kamezaki K, Miyamoto T, Harada N, Nagafuji K, et al. Successful treatment of primary cardiac lymphoma by rituximab-CHOP and high-dose chemotherapy with autologous peripheral blood stem cell transplantation. Int $\mathrm{J}$ Hematol. 2007; 85(3): 264-6. 